\title{
Intramuscular triglyceride content is increased in IDDM
}

\author{
P. Ebeling ${ }^{1}$, B. Esse $<$ 'n-Gustavsson ${ }^{2}$, J. A. Tuominen ${ }^{1}$, V. A. Koivisto ${ }^{1}$ \\ ${ }^{1}$ Department of Medicine, University of Helsinki, Helsinki, Finland \\ ${ }^{2}$ Swedish University of Agricultural Sciences, Uppsala, Sweden
}

Summary Increased lipid oxidation is related to insulin resistance. Some of the enhanced lipid utilization may be derived from intramuscular sources. We studied muscle triglyceride (mTG) concentration and its relationship to insulin sensitivity in 10 healthy men (age $29 \pm 2$ years, BMI $23.3 \pm 0.6 \mathrm{~kg} / \mathrm{m}^{2}$ ) and 17 men with insulin-dependent diabetes mellitus (IDDM) (age $30 \pm 2$ years, BMI $22.8 \pm 0.5 \mathrm{~kg} / \mathrm{m}^{2}$, diabetes duration $14 \pm 2$ years, $\mathrm{HbA}_{1 \mathrm{c}} 7.7 \pm 0.3 \%$, insulin dose $48 \pm 3 \mathrm{U} /$ day). Insulin sensitivity was measured with a $4 \mathrm{~h}$ euglycaemic $(5 \mathrm{mmol} / \mathrm{l})$ hyperinsulinaemic $\left(1.5 \mathrm{mU}\right.$ or $\left.9 \mathrm{pmol} \cdot \mathrm{kg}^{-1} \cdot \mathrm{min}^{-1}\right)$ clamp accompanied by indirect calorimetry before and at the end of the insulin infusion. A percutaneous biopsy was performed from $\mathrm{m}$. vastus lateralis for the determination of mTG. At baseline the IDDM patients had higher glucose $(10.2 \pm 0.9$ vs $5.6 \pm 0.1 \mathrm{mmol} / \mathrm{l}$, $p<0.001)$, insulin $(40.3 \pm 3.2$ vs $23.2 \pm 4.2 \mathrm{pmol} / 1, p<$ $0.01)$, HDL cholesterol (1.28 \pm 0.06 vs $1.04 \pm$ $0.03 \mathrm{mmol} / \mathrm{l}, p<0.01)$ and $\mathrm{mTG}(32.9 \pm 4.6$ vs $13.6 \pm$
$2.7 \mathrm{mmol} / \mathrm{kg}$ dry weight, $p<0.01)$ concentrations than the healthy men, respectively. The IDDM patients had lower insulin stimulated whole body total $(--25 \%, p<0.001)$, oxidative $(--18 \%, p<0.01)$ and non-oxidative glucose disposal rates $(--43 \%, p<$ 0.001 ), whereas lipid oxidation rate was higher in the basal state $(+44 \%, p<0.01)$ and during hyperinsulinaemia $(+283 \%, p<0.05)$. mTG concentrations did not change significantly during the clamp or correlate with insulin stimulated glucose disposal. In healthy men mTG correlated positively with lipid oxidation rate at the end of hyperinsulinaemia $(r=0.75, p<0.05)$. In conclusion: 1$)$ IDDM is associated with increased intramuscular TG content. 2) mTG content does not correlate with insulin sensitivity in healthy subjects or patients with IDDM. [Diabetologia (1998) 41: 111--115]

Keywords Type 1 diabetes, muscle, triglycerides, insulin sensitivity, lipid oxidation.
Increased lipid oxidation is related to insulin resistance [1]. Most of the fatty acids taken up by resting muscle are not oxidized directly, but enter an intramuscular pool with a slow turnover at rest and are the immediate source of lipid substrate for oxidation [2]. The NEFA taken up by muscle are incorporated

Received: 12 June 1997 and in revised form: 8 September 1997

Corresponding author: P. Ebeling, M.D., Helsinki University Hospital, Department of Medicine, Haartmaninkatu 4, 00290 Helsinki, Finland

Abbreviations: CVD, Cardiovascular disease; HDL, high density lipoprotein; IDDM, insulin-dependent diabetes mellitus; mTG, muscle triglyceride; NEFA, non-esterified fatty acids. to lipid droplets in muscle and $70--90 \%$ of fatty acids entering the muscle are rapidly esterified to triglyceride (TG) [3]. For example, raising extracellular palmitate increases esterification, but does not increase intramuscular concentration of palmitate [4]. Part of the enhanced lipid oxidation can be derived from intramuscular sources [5].

As compared to healthy subjects a sixfold increase of muscle (m) TG in patients with non-insulin-dependent diabetes mellitus [6], and a sevenfold increase in TG content in striated muscle in coronary bypass-operated patients with impaired glucose tolerance [7] have been reported in comparison to control groups. These patient groups are also characterized by insulin resistance. Sustained euglycaemic hyperinsulinaemia 
due to islet autografts draining into the systemic circulation leads to a fourfold increase of intramuscular TG and twentyfold TG concentration in the arterial wall in dogs [8]. This is associated with increased insulin response to a glucose load thus reflecting insulin resistance. Elevated mTG levels have been reported for IDDM patients after withdrawal of insulin for $24 \mathrm{~h}$ [9]. Furthermore, an inverse association of mTG and insulin sensitivity has been reported in Pima Indians [10]. In rats a high fat diet caused insulin resistance and insulin sensitivity was inversely related to mTG concentration [11].

A majority of IDDM patients are characterized by insulin resistance [12]. Consequently, we wanted to study whether the amount of mTG is altered in IDDM, and if $\mathrm{mTG}$ are related to insulin sensitivity in healthy men and in patients with IDDM. We also examined the effect of acute hyperinsulinaemia with a low circulating NEFA level on mTG content.

\section{Subjects, design and methods}

Subjects. Ten healthy men (age $29 \pm 2$ years, BMI $23.3 \pm 0.6 \mathrm{~kg} /$ $\mathrm{m}^{2}$ ) and 17 men with IDDM (age $30 \pm 2$ years, BMI $22.8 \pm 0.5$ $\mathrm{kg} / \mathrm{m}^{2}$, diabetes duration $14 \pm 2$ years, $\mathrm{HbA}_{1 \mathrm{c}} 7.7 \pm 0.3 \%$ (normal range $4.0--6.0 \%$ ), insulin dose $48 \pm 3$ U/day) participated in the study. The participants were asked not to do any intensive exercise for at least 2 days prior to the study. None of the patients had clinical signs of nephropathy, neuropathy or proliferative retinopathy, and no one used any other medication, except insulin. The patients were asked to monitor their blood glucose on the previous day and adjust their diet if necessary in order to achieve a fasting blood glucose level of $6--10 \mathrm{mmol} / 1$ on the study day. The purpose, nature and possible risks of the study were explained to all the subjects before informed consent was obtained. The study protocol was approved by the ethical committee of the Helsinki University Central Hospital.

Design and methods. After an overnight fast, a $4 \mathrm{~h}$ euglycaemic ( $5 \mathrm{mmol} / \mathrm{l})$ hyperinsulinaemic clamp was performed by infusing short-acting insulin (Actrapid; Novo Nordisk, Denmark, $1.5 \mathrm{mU}$ or $\left.9 \mathrm{pmol} \cdot \mathrm{kg}^{-1} \cdot \mathrm{min}^{-1}\right)$ as previously described $[13,14]$. Indirect calorimetry was performed before and at the end of the insulin infusion for the determination of glucose and lipid oxidation [15]. The protein oxidation was estimated on basis of the urea nitrogen excretion during the insulin infusion. In one healthy subject no calorimetric data were obtained. Glucose disposal rate was calculated from the glucose infusion rate of the last hour of the clamp. Nonoxidative glucose disposal rate was calculated by subtracting glucose oxidation from glucose infusion rate. Blood samples for glucose measurements (Beckman glucose analyzer; Beckman Instruments, Fullerton, Calif., USA) were taken from an arterialized vein before and at 5 to 10 min intervals during insulin infusion. A percutaneous muscle biopsy was performed with a Bergström needle under local anaesthesia (1\% lidocaine). The samples were obtained from vastus lateralis muscle from opposite sides before and at the end of hyperinsulinaemia for the determination of mTG from all healthy subjects and 10 patients with IDDM. From 5 IDDM patients only preclamp and from 2 patients only postclamp specimens were
Table 1. Circulating substrate and hormone concentrations, $\mathrm{VO}_{2} \mathrm{max}$ and percentage body fat in the basal state in the control subjects and diabetic patients

\begin{tabular}{lcc}
\hline & $\begin{array}{c}\text { Control } \\
\text { subjects }\end{array}$ & Patients \\
\hline Glucose $(\mathrm{mmol} / \mathrm{l})$ & $5.6 \pm 0.1$ & $10.2 \pm 0.9^{\mathrm{b}}$ \\
Insulin $(\mathrm{pmol} / \mathrm{l})$ & $23.2 \pm 4.2$ & $40.3 \pm 3.2^{\mathrm{a}}$ \\
Growth hormone $(\mu \mathrm{g} / \mathrm{l})$ & $4.5 \pm 2.0$ & $9.5 \pm 3.8$ \\
Cortisol $(\mathrm{nmol} / \mathrm{l})$ & $358 \pm 49$ & $3.91 \pm 29$ \\
Total cholesterol $(\mathrm{mmol} / \mathrm{l})$ & $3.8 \pm 0.2$ & $4.1 \pm 0.2$ \\
HDL cholesterol $(\mathrm{mmol} / \mathrm{l})$ & $1.04 \pm 0.03$ & $1.28 \pm 0.06^{\mathrm{a}}$ \\
Triglycerides $(\mathrm{mmol} / \mathrm{l})$ & $0.74 \pm 0.06$ & $0.67 \pm 0.05$ \\
$\mathrm{VO}_{2}$ max $\left(\mathrm{ml} \cdot \mathrm{kg}^{-1} \cdot \mathrm{min}^{-1}\right)$ & $47.8 \pm 2.5$ & $45.6 \pm 1.6$ \\
Fat $(\%)$ & $9.3 \pm 0.9$ & $8.8 \pm 0.7$ \\
\hline
\end{tabular}

${ }^{\mathrm{a}} p<0.01 ;{ }^{\mathrm{b}} p<0.001$ for differences between groups

Data are mean \pm SEM

obtained. Before the insulin infusion a blood sample was taken for the measurement of growth hormone [16], cortisol [17], TG [18], cholesterol [19] and HDL cholesterol [20]. Serum NEFA were determined both in the basal state and at the end of insulin infusion [21]. Serum insulin was measured radioimmunologically [22]. TG content was determined on freeze-dried muscle tissue (duplicate samples weighing 1 to $2 \mathrm{mg}$ ) dissected free from blood, lipid droplets and connective tissue as previously described [23]. The muscle tissue was extracted in chloroform/methanol (Folch extract) and after separation the chloroform phase was retained and evaporated. Hydrolysis of TG was performed with tetraetyl ammoniumhydroxide solution and the glycerol content was determined. Appropriate tripalmitin standards were treated in the same manner as the muscle samples. Maximal aerobic power $\left(\mathrm{VO}_{2} \max \right)$ was determined using a work-conducted upright exercise test [14]. The estimation of body fat was calculated by summing up six skinfolds [24].

Statistical analysis. In the statistical analyses the Mann-Whitney $U$ test was used for comparisons between the groups and the Wilcoxon's signed rank test was used for comparisons between paired items. Correlation analysis was done with the Spearman test. $P$-values less than 0.05 were considered significant. The results are given as mean \pm SEM.

\section{Results}

The baseline laboratory findings of the healthy subjects and diabetic patients are given in Table 1. The mean insulin concentration during the insulin infusion was slightly lower in the diabetic patients $(564 \pm 24 \mathrm{pmol} / \mathrm{l})$ than in the healthy men $(640 \pm 36$ $\mathrm{pmol} / \mathrm{l}, p<0.05)$. Basal glucose oxidation $(8.0 \pm 1.1$ vs $6.0 \pm 0.7 \mu \mathrm{mol} \cdot \mathrm{kg}^{-1} \cdot \mathrm{min}^{-1}$, control subjects vs IDDM) was not significantly different between the groups. In the insulin-stimulated state IDDM patients had a lower whole body total glucose disposal $\left(43.5 \pm 2.4\right.$ vs $67.0 \pm 3.7 \mu \mathrm{mol} \cdot \mathrm{kg}^{-1} \cdot \mathrm{min}^{-1}, p<$ $0.001)$, oxidative $\left(17.2 \pm 0.8\right.$ vs $21.0 \pm 1.5 \mu \mathrm{mol} \cdot \mathrm{kg}^{-1}$. $\left.\min ^{-1}, p<0.01\right)$ and non-oxidative glucose disposal $\left(26.3 \pm 2.2\right.$ vs $46.0 \pm 3.5 \mu \mathrm{mol} \cdot \mathrm{kg}^{-1} \cdot \mathrm{min}^{-1}, p<$ $0.001)$ than healthy subjects, respectively. Lipid oxi- 


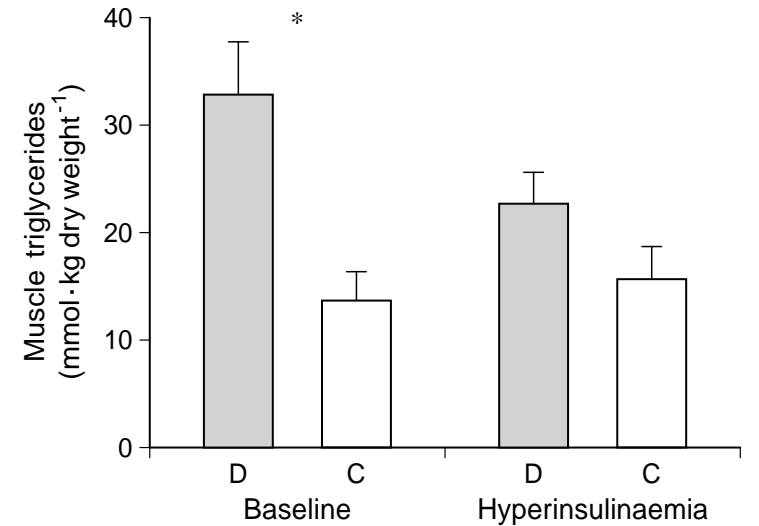

Fig. 1. Muscle triglyceride concentration before and at the end of hyperinsulinaemia in the diabetic patients and control subjects $\square . * p<0.01$

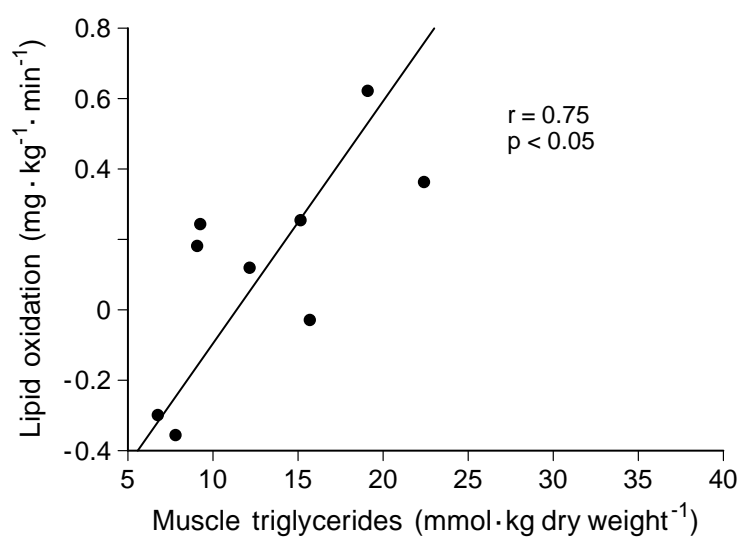

Fig. 2. Correlation between muscle triglyceride content and lipid oxidation rate at the end of hyperinsulinaemia in the healthy men

dation rate was elevated in the diabetic patients both in the basal $(1.18 \pm 0.05$ vs $0.82 \pm 0.10, p<$ $\left.0.01 \mu \mathrm{mol} \cdot \mathrm{kg}^{-1} \cdot \mathrm{min}^{-1}\right)$ and hyperinsulinaemic $\left(0.46 \pm 0.07\right.$ vs $\left.0.12 \pm 0.10 \mathrm{mg} \cdot \mathrm{kg}^{-1} \cdot \mathrm{min}^{-1}, p<0.05\right)$ states. Serum NEFA levels varied in the diabetic patients in the basal (range 307 to $1707 \mu \mathrm{mol} / \mathrm{l}$ ) and insulin suppressed state (range from 28 to $260 \mu \mathrm{mol} / \mathrm{l}$ ). There was no statistically significant difference between diabetic patients and the healthy subjects in the mean serum NEFA concentrations either in the basal $(789 \pm 90$ vs $506 \pm 79 \mu \mathrm{mol} / \mathrm{l}$ vs $p=0.06)$ or hyperinsulinaemic state $(96 \pm 14$ vs $104 \pm 7 \mu \mathrm{mol} / \mathrm{l}$, respectively). MTG content was 2.4 times higher in the diabetic patients than control subject before the insulin infusion (Fig.1). MTG concentrations did not change significantly during the clamp, but at the end of hyperinsulinaemia the baseline difference in mTG between the groups had vanished (Fig.1). In the healthy control subjects lipid oxidation at the end of hyperinsulinaemia correlated with postclamp mTG content (Fig. 2). There was no correlation between basal mTG and whole body glucose disposal in the diabetic $(r=--0.02)$ or healthy subjects $(r=--$ $0.03)$.

\section{Discussion}

In the current study we addressed the following questions. First, is there any difference in $\mathrm{mTG}$ concentrations between IDDM patients and healthy men? Second, is mTG content associated with insulin resistance or serum lipid or hormone concentrations and third, has euglycaemic hyperinsulinaemia any effect on muscle TG content?

Our diabetic patients had higher fasting glucose and insulin levels than the healthy men and they were insulin resistant in comparison to the control subjects, as previously reported for patients with IDDM [12]. The slightly elevated HDL cholesterol in the patients is in accordance with previous reports on HDL cholesterol in well-controlled IDDM patients [25].

Regarding lipid metabolism, the IDDM patients had elevated lipid oxidation rates both in the basal state and during hyperinsulinaemia. This is in agreement with their insulin resistance, because NEFA have an inhibitory effect on many key enzymes in glucose metabolism [26]. Lipid oxidation consists of oxidation of intracellular lipids and blood-borne fatty acids [27]. Accordingly, at baseline the mTG concentration was higher in the IDDM patients than control subjects and also their NEFA tended to be higher. At the end of hyperinsulinaemia mTG was not significantly higher in IDDM patients and the difference in serum NEFA was totally abolished. A correlation between lipid oxidation rate and the concentration of either of these sources of NEFA was found only in the control subjects. At the end of hyperinsulinaemia lipid oxidation rate correlated with mTG. mTG concentrations in the basal state or during hyperinsulinaemia were not related to insulin sensitivity in either group and serum TG concentrations were the same in both groups.

Several factors may account for the high basal mTG content in the IDDM patients. First, high fat diet can lead to elevated mTG concentration [23, 28]. Our IDDM patients, however, were on a recommended diabetic diet without excessive dietary fat. Second, both heavy resistance exercise [29] and exercise to exhaustion [30] can result in acutely reduced mTG concentrations. Our subjects and patients were studied after an overnight fast without preceding exercise. Third, our diabetic patients had elevated glucose and insulin concentrations in the basal state. Elevated $\mathrm{mTG}$ have been reported in healthy euglycaemic hyperinsulinaemic dogs [8] and pigs [31]. In the dogs this occurred despite reduced serum TG concentration in the hyperinsulinaemic animals. In coronary bypass-operated patients with impaired glucose tolerance, fasting insulin concentration was elevated and 
triglyceride content in the aortic wall and striated muscle were elevated in comparison to control subjects. Elevated tissue TG accumulation was not seen in patients with normal glucose tolerance [7]. Falholt and co-workers [6] observed also a sixfold elevated muscle TG content in NIDDM patients. In addition to hyperglycaemia, the NIDDM patients had hyperinsulinaemia, which is a common factor for all of these situations characterized by elevated mTG. However, insulin withdrawal for $24 \mathrm{~h}$ in poorly controlled patients with IDDM was also associated with elevated serum glucose, TG and NEFA concentrations and with elevated mTG content [9]. Thus, peripheral hyperinsulinaemia and hyperglycaemia may contribute to the elevated $\mathrm{mTG}$ concentrations in our IDDM patients.

The disappearance of the difference in MTG content between our patients and healthy subjects during hyperinsulinaemia is in accordance with an intramuscular source of fatty acids with a slow turnover rate [2]. In the current study serum NEFA concentrations were equal in the two groups at the end of insulin infusion. Most of the reduction in serum NEFA during a hyperinsulinaemia of $4 \mathrm{~h}$ is seen already during the first $30 \mathrm{~min}$ of insulin infusion [14]. Because most of the NEFA taken up by muscle are rapidly esterified to TG [3], equally low concentrations of NEFA in serum despite higher lipid oxidation rate in IDDM would be expected to lead to greater reduction of mTG in IDDM than control subjects. Although there was no significant change in the mean $\mathrm{mTG}$ content in either group, the mTG content in IDDM patients was not significantly higher than in healthy subjects at the end of hyperinsulinaemia. Thus, the disappearance of the difference in mTG content between IDDM and healthy subjects suggests increased use of $\mathrm{mTG}$ as a substrate for lipid oxidation in IDDM patients. The lack of correlation between mTG content and insulin mediated glucose disposal could reflect the fact that not only NEFA derived from mTG, but also blood-borne NEFA contribute to the lipid oxidation. It must be emphasised that indirect calorimetry estimates whole body glucose and lipid oxidation and not specifically skeletal muscle oxidation. A recent study in NIDDM patients has suggested that muscle lipid oxidation in NIDDM patients under clinical hyperglycemic conditions is not different from healthy individuals [32]. Considering that also NIDDM patients have elevated mTG, it is possible that elevated lipid oxidation rate at baseline in our IDDM patients is due to tissues other than skeletal muscle, such as the liver.

Acknowledgements. The skilful technical assistance of Ms. E. Kostamo is appreciated. The study was supported by the Paulo Foundation, the Yrjö Jahnsson Foundation, the University of Helsinki, the Maud Kuistila Foundation, the Finnish Academy of Science and Novo Nordisk Foundation.

\section{References}

1. Groop LC, Bonadonna RC, Simonson DC, Petrides AS, Shank M, DeFronzo RA (1992) Effect of insulin on oxidative and nonoxidative pathways of free fatty acid metabolism in human obesity. Am J Physiol 263:E79--E84

2. Dagenais GR, Tancredi RG, Zierler KL (1976) Free fatty acid oxidation by forearm muscle at rest, and evidence for an intramuscular lipid pool in the human forearm. J Clin Invest 58: 421--431

3. Oscai LB, Essig DA, Palmer WK (1990) Lipase regulation of muscle triglyceride hydrolysis. J Appl Physiol 69: 1571-1577

4. Schonfeld G, Kipnis DM (1966) Studies of extracellular and tissue fatty acid pools and glucose metabolism in striated muscle. J Clin Invest 45: 1071

5. Yki-Järvinen H, Puhakainen I, Koivisto VA (1991) Effect of free fatty acids on glucose uptake and nonoxidative glycolysis across human forearm tissues in the basal state and during insulin stimulation. J Clin Endocrinol Metab 72:1268--1277

6. Falholt K, Jensen I, Lindkaer Jensen S et al. (1987) Carbohydrate and lipid metabolism of skeletal muscle in type 2 diabetic patients. Diabet Med 5: 27--31

7. Falholt K, Hjelms E, Jensen I, Voelund A, Heding LG, Falholt W (1987) Intracellular metabolism in biopsies from the aorta in patients undergoing coronary bypass surgery. Diabete Metab 13: 312--317

8. Falholt K, Cutfield R, Alejandro R, Heding L, Mintz D (1985) The effects of hyperinsulinemia on arterial wall and peripheral muscle metabolism in dogs. Metabolism 34: 1146--1149

9. Standl E, Lotz N, Dexel T, Janka H-U, Kolb HJ (1980) Muscle triglycerides in diabetic subjects. Effect of insulin deficiency and exercise. Diabetologia 18: 463--469

10. Pan DA, Lillioja S, Kriketos AD et al. (1997) Skeletal muscle triglyceride levels are inversely related to insulin action. Diabetes 46: 983--988

11. Storlien LH, Jenkins AB, Chisholm DJ, Pascoe WS, Khouri S, Kraegen EW (1991) Influence of dietary fat composition on development of insulin resistance in rats. Relationship to muscle triglyceride and w-3 fatty acids in muscle phospholipid. Diabetes 40: 280--289

12. Yki-Järvinen H, Koivisto VA (1986) Natural course of insulin resistance in type I diabetes. N Engl J Med 315: 224-230

13. DeFronzo RA, Tobin JD, Andres R (1979) Glucose clamp technique: a method for quantifying insulin secretion and resistance. Am J Physiol 237:E214-E223

14. Ebeling P, Bourey R, Koranyi L et al. (1993) Mechanism of enhanced insulin sensitivity in athletes: Increased blood flow, muscle glucose transport protein (GLUT-4) concentration and glycogen synthase activity. J Clin Invest 92: 1623--1631

15. Ferrannini E (1988) The theoretical bases of indirect calorimetry: a review. Metabolism 37: 287--301

16. Laron Z, Mannheimer S (1966) Measurement of human growth hormone. Isr J Med Sci 2: 115--119

17. Rolleri E, Zannino M, Orlandini S, Malvano R (1976) Direct radioimmunoassay of plasma cortisol. Clin Chim Acta 66: 319--330

18. Bergmeier HU (1974) Metoden der enzymatischen Analyse. 3. Auflage, Bd II, Verlag Chemie Weinheim:1878

19. Siedel J, Hägele EO, Ziegenhorn J, Wahlefeld AW (1983) Reagent for the enzymatic determination of serum total 
cholesterol with improved lipolytic efficiency. Clin Chem 29: $1075--1080$

20. Finley PR, Schifman RB, Williams RJ, Lichti DA (1978) Cholesterol in high-density lipoprotein: use of $\mathrm{Mg} 2+/ \mathrm{dex}-$ tran sulfate in its enzymic measurement. Clin Chem 26: 931--933

21. Miles J, Glasscock R, Aikens J, Gerich J, Haymond M (1983) Microfluorometric method for the determination of free fatty acids in plasma. J Lipid Res 24: 96--99

22. Desbuquois B, Aurbach GD (1971) Use of polyethylene glycol to separate free and antibody-bound peptide hormones in radioimmunoassays. J Clin Endocr 33: 732--738

23. Kiens B, Esse<'n-Gustavsson B, Gad P, Lithell H (1987) Lipoprotein lipase activity and intramuscular triglyceride stores after long-term high-fat and high-carbohydrate diets in physically trained men. Clin Physiol 7: 1--9

24. Anyan WRJ (1978) Adolescent medicine in primary care. Wiley, New York, p. 137

25. Nikkilä EA, Hormila P (1978) Serum lipids and lipoproteins in insulin-treated diabetes. Demonstration of increased high density lipoprotein concentrations. Diabetes 27: 1078--1086
26. Randle PJ, Priestman DA, Mistry S, Halsall A (1994) Mechanisms modifying glucose oxidation in diabetes mellitus. Diabetologia 37[Suppl 2]:S155--S161

27. Groop LC, Bonadonna RC, Shank M, Petrides AS, DeFronzo RA (1991) Role of free fatty acids and insulin in determining free fatty acid and lipid oxidation in man. $\mathrm{J}$ Clin Invest 87: 83--89

28. Jansson E, Kaijser L (1982) Effect of diet on the utilization of blood-borne and intramuscular substrates during exercise in man. Acta Physiol Scand 115: 19--30

29. Esse <'n-Gustavsson B, Tesch PA (1990) Glycogen and triglyceride utilization in relation to muscle metabolic characteristics in men performing heavy-resistance exercise. Eur J Appl Physiol 61: 5--10

30. Carlson LA, Ekelund L-G, Fröberg SO (1971) Concentrations of triglycerides, phospholipids and glycogen in skeletal muscle and of free fatty acids and B-hydroxybutyric acid in blood in man in response to exercise. Eur J Clin Invest 1: 248--254

31. Falholt K, Alberti KGMM, Heding LG (1985) Aorta and muscle metabolism in pigs with peripheral hyperinsulinaemia. Diabetologia 28: 32--37

32. Mandarino LJ, Consoli G, Jain A, Kelley DE (1996) Interaction of carbohydrate and fat fuels in human skeletal muscle: impact of obesity and NIDDM. Am J Physiol 270:E463--E470 